\title{
PREPARATION OF SAMPLES USED IN FATIGUE TESTING OF AIRCRAFT MATERIALS
}

\author{
Wojciech Manaj \\ Wojciech Wronicz \\ Andrzej Michałowski \\ Institute of Aviation, Al. Krakowska 110/114, 02-256 Warsaw, Poland \\ wojciech.manaj@ilot.edu.pl, wojciech.wronicz@ilot.edu.pl, andrzej.michalowski@ilot.edu.pl
}

\begin{abstract}
The application of a new type of alloy requires the evaluation of its properties, which is typically achieved with destructive methods. For this purpose, among others, static and fatigue mechanical tests are performed. Tests are performed on standardized samples in a way which reflects the level of stress occurring in real elements. These tests should limit random errors associated with sample preparation. For this reason the proper preparation of samples is crucial, not only in terms of their geometric dimensions but also in terms of the residual stress level. A sample preparation process was developed, involving checking samples' surface for cracks, scratches, roughness, and the state of stress. The measurements are performed with nondestructive methods so as not to affect the proceeding research.

In this study, the residual stress and features of a mechanically prepared surface were characterized. The specimens were subjected to various surface finishes mainly, lathe turning and grinding surface conditions. The effects of residual surface stress (measured by XRD) were studied after machining and polishing.
\end{abstract}

Keywords: mechanical processing, stress measurement, X-ray diffraction.

\section{INTRODUCTION}

The application of a new type of alloy is preceded by the evaluation of its properties, which is typically achieved by destructive methods. For this purpose, inter alia, strength and cyclic loading testing are applied. Fatigue is an important parameter to be considered in the behavior of components subjected to variable amplitude loading. Engineering components and structures are regularly subjected to cyclic loading and are consequently prone to fatigue damage. In most cases, fatigue damage starts on the surface due to localized stress concentrations [1,2] caused by machining marks, exposed inclusions or even the contrasting movement of dislocations. It is estimated that fatigue is responsible for $80 \%$ to $90 \%$ of all engineering failures [3].

The fatigue strength of materials is affected by a variety of factors such as the amount of porosity and microstructure. According to some studies, the presence of $10 \%$ porosity decreased the fatigue strength of steels by $25 \%$ to $50 \%[4]$. The surface condition can play a vital role in fatigue strength too. For example, Sonsino et al $[5,6]$ have shown that surface rolling and shotpeening can improve the fatigue strength of sintered steels by roughly $20 \%$ due to surface densification and the introduction of residual compressive stresses on the surface. In wrought steels, the surface condition, and hence fatigue strength, are affected by machining. For example, milled tool steel samples have a 35\% higher fatigue strength than those machined by EDM, 
because EDM causes cracking and residual tensile stresses on the surface[7]. The effect of surface finish on the fatigue strength of low carbon steel has been shown by Obiukwu et al [8].

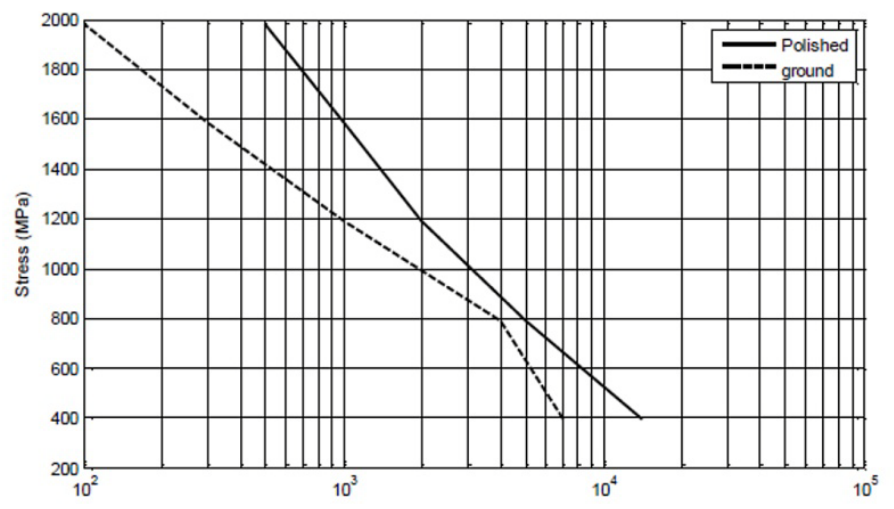

Figure 1. Stress values and fatigue strength in relation to a type of machining

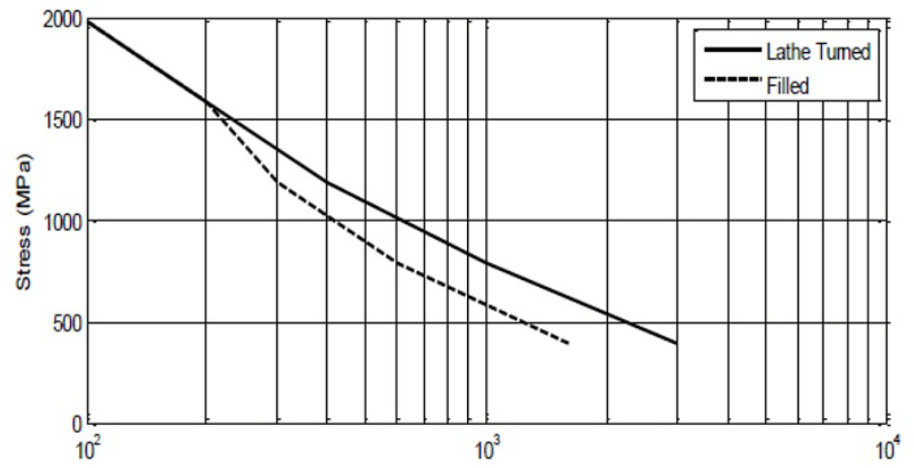

Figure 2. Stress values and fatigue strength in relation to a type of machining

For this purpose, tests are performed on standardized samples in a way which reflects the level of stress in real elements. These tests should limit random errors associated with sample preparation. Proper preparation of samples is crucial, not only in terms of their geometric dimensions but also in terms of the stress level, roughness and sample surface (verification of the samples surface for cracks scratches).

\section{METHODOLOGY AND RESULTS}

Low carbon steel and $\mathrm{Ni}$ alloy were selected for studying the effect of surface finish on the residual stress level. Standard fatigue specimens were prepared according to ASTM E466-15. The population of specimens after turning (series A) and after turning and grinding (series B) was tested. In this study, the residual stresses of a mechanically prepared surface were characterized. The residual stress measurements were made in the measuring parts of samples. For each measuring point, measurements were performed in the axial direction of the sample. The research methodology was consistent with the EN 15305: 2008 standard. The results of the measurements are provided in Table 1.

Table 1. The results of stress measurements in the turned and turned and ground samples

\begin{tabular}{|c|c|c|}
\hline Samples & $\begin{array}{c}\text { Average } \\
\sigma[\mathrm{MPa}]\end{array}$ & $\begin{array}{c}\text { Standard deviation } \\
\sigma[\mathrm{MPa}]\end{array}$ \\
\hline $\mathrm{Ni}-\mathrm{A}$ & -107 & 255 \\
\hline $\mathrm{Ni}-\mathrm{B}$ & -516 & 17 \\
\hline $\mathrm{Fe}-\mathrm{A}$ & 125 & 57 \\
\hline $\mathrm{Fe}-\mathrm{B}$ & -472 & 20 \\
\hline
\end{tabular}




\section{SUMMARY AND CONCLUSIONS}

The residual stress of low carbon steel and $\mathrm{Ni}$ alloy specimens was determined using the XRD method. Different levels of residual stresses were observed in Ni-alloy and low carbon steel after the same type of machining. The residual stress after grinding was lower for both materials. The samples preparation recurrence was higher in turned and ground samples. Thus, it can be concluded that the turned and ground samples increase the reliability and repeatability of fatigue tests.

\section{REFERENCES}

[1] Gadalińska E., Kaniowski J., X-ray diffraction measurements for riveted joints. Application of the novel methodology; Fatigue of Aircraft Structures, Issue 2012, pp. 18-39.

[2] Elżbieta Gadalińska, Andrzej Baczmański, Micromechanical Properties and Stress Measurements with Diffraction Methods; Fatigue of Aircraft Structures, Issue 2013, pp. 17-29.

[3] Fatemi A. and Yang L., 1998," Cumulative Fatigue Damage and Life Prediction Theories: a Survey of the State of The Art for Homogeneous Material", International Journal of Fatigue, vol. 20, pp 9-34.

[4] N. Chawla and X. Deng, "Microstructure and Mechanical Behavior of Porous Sintered Steels", Mater. Sci. Eng. A 390 (2005) 98-112.

[5] C.M. Sonsino, F. Müller and R. Mueller, "The Improvement of Fatigue Behaviour of Sintered Steels by Surface Rolling”, Int. J. Fatigue 14[1] (1992) 3-13.

[6] C.M. Sonsino, F. Müller, V. Arnhold and G. Schlieper, "Influence of Mechanical Surface Treatments on the Fatigue Properties of Sintered Steels under Constant and Variable Amplitude Loading”, Mod. Dev. Pow. Metall. 21 (1988) 55-66.

[7] F. Ghanem, C. Braham, M.E. Fitzpatrick, and H. Sidhom, "Effect of Near-Surface Residual Stress and Microstructure Modification from Machining on the Fatigue Endurance of a Tool Steel”, J. Mater. Eng. Perf. 11(6) 2002 631-639.

[8] O. Obiukwu, M. Nwafor, B. Okafor, L. Grema "The effect of surface finish on the low cycle fatigue of low and medium carbon steel, International Conference on Mechanical and Industrial Engineering (ICMIE'15) July 14-15, 2015 Harare (Zimbabwe). 